\title{
VEINTE AÑOS DE REVOLUCIÓN NEO-LIBERAL De la Estrategia de Lisboa a Europa 2020
}

\author{
Francesco Maniglio ${ }^{12}$ \\ Centro Internacional de Estudios Superiores de Comunicación para América Latina (CIESPAL) \\ www.ciespal.org
}

http://dx.doi.org/10.5209/rev NOMA.2016.v47.n1.52406

\begin{abstract}
Resumen.- Los estudios socio-políticos respecto a las conformaciones tecnocráticas en la UE permiten destacar un sistema de gobernanza a la luz de la alianza de clase entre la comunidad epistémica, la clase política clásica, los lobbies económicos y financieros. Esta alianza marca una revolución neo-liberal en la naturaleza del poder y una posición dominante en el proceso histórico hegemónico. En este articulo proponemos la análisis de las dinámicas históricopolíticas a través de las cuales, desde la Estrategia de Lisboa, la gobernanza europea construye y expande los mecanismos de subsunción al capital, imponiendo los ajustes y las reformas estructurales que están transformando nuestros modos de vida en ganancia y miseria.
\end{abstract}

Palabras clave: Nueva Gobernanza; Empleabilidad; Flexiseguridad; EEES; EEE; Estrategia de Lisboa; Proceso de Bolonia; Europa 2020

\begin{abstract}
The socio-political studies concerning the technocratic conformations in the EU enable the emphasis on a governance system in the light of the class analysis between the epistemic community, the traditional political class, the economic and financial lobbies. This alliance sets a neo-liberal revolution in the nature of power and a dominant position in the hegemonic historical process. In this article we propose the analysis of the historical and political dynamics through which, since the Lisbon Strategy, the european governance constructs and expands the mechanisms of subsumption under capital, imposing the adjustments and the structural reforms that are transforming our lifestyles in greed and misery.
\end{abstract}

Keywords: New Gobernance; Employability, Elexsecurity; EHEA; EES; Lisbon Strategy, Bologna Process; Europe 2020

\section{Introducción}

Europeans are in the process of constructing a "new Europe" on the foundations of improved competitiveness and a dynamic, knowledge-based economy that will ultimately extend over a significantly larger group of countries than the present 15 members of the European Union. Competitive advantage in the knowledge economy no longer relates purely to a product or service. It is much more dependent on the continuous acquisition of new skills by people and companies and being ahead of the competition in exploiting critical knowledge (ERT 2001:3).

Tras los últimos veinte años se ha marcado una profunda transformación en la manera en que la Unión Europea funciona a nivel político-gubernamental. Esta transformación, más allá de la unificación del mercado común, ha coincidido con una significativa e importante expansión de las actividades comunitarias. La UE ha empezado a tener intereses no solo en la reglamentación económica, sino poco a poco en las principales áreas político-sociales en las que

\footnotetext{
${ }^{1}$ El presente trabajo fue patrocinado por el proyecto Proyecto de la Secretaria de Educación Superior, Ciencia, Tecnología e Innovación (SENESCYT) de la Republica de Ecuador.

${ }^{2}$ Es investigador en el Centro Internacional de Estudios Superiores de Comunicación para América Latina (CIESPAL) por el Proyecto de la Secretaria de Educación Superior, Ciencia, Tecnología e Innovación (SENESCYT) de Ecuador. Es doctor en Comunicación y Crítica de la Cultura por la Universidad de Sevilla (España), master en Filosofía del Derecho por la Universidad Pablo de Olavide (España).
} 
originalmente no tenía competencia. Esta expansión, que en un primer momento ha evolucionado sin el sustento de una base legal sólida, sucesivamente ha sido ratificada por una serie de modificaciones en los varios tratados constitutivos, con la finalidad de resolver las carencias de legitimidad. Sin embargo, la obra de europeización, o sea la gradual transferencia de las competencias desde el nivel nacional al comunitario, ha sido no solo una obra de carácter formal sino más bien un proceso constituyente que altera sustancialmente el modelo de gobernanza ${ }^{3}$.

Policy-making in the EU is not the same as in a domestic state. There is no central agenda-setting and coordinating actor, like the chief executive in a presidential system or the governing party in a parliamentary system (Peters 1994). The process, from initiation through adaptation to implementation is complex and involves constant deliberation and cooperation between several levels of state and non-state officials In the adoptation stage, the need to satisfy a myriad of territorial and functional constituencies requires open 'policy communities/networks', where private interest groups are active and equal participants, along side European, national and subnational state officials (Mazey and Richardson 1993a, 1995; Peterson 1995a, 1995b; Peterson and Bomberg 1997) (Hix 1998:343).

La Estrategia Europea de Empleo (EEE) es quizá la más representativa de esta etapa de la gobernanza europea por lo que concierne la metodología de acción-sanción (denominada método abierto o MAC) (Martinico 2009) ${ }^{4}$. Es bajo esta metodología política que, entre finales del siglo pasado y la presente década, se manifiesta la hegemonía neoliberal del techno-corporatism ${ }^{5}$ europeo, al elaborar planes de ajustes y reformas estructurales a largo plazo (decenales), despotenciando así cualquier advenimiento político y social en el hic et nunc (elecciones nacionales, referéndum, olas de oposiciones, movimientos sociales de protestas) de la dialéctica decisoria. La ERT (European Round Table of Industrialists) en Enhancing European Competitiveness-our core concern (ERT 2000), presiona al Consejo Europeo de Noordwijk, celebrado el 9 y 10 marzo de 2000 para que se reformen los procesos administrativos y estructurales de la gobernanza europea:

\footnotetext{
${ }^{3}$ Este fenómeno que definimos de agencification, describe un proceso de transferencia de actividades de gobierno a agencias especializadas y organizadas verticalmente fuera de los departamentos ministeriales. A nivel europeo, se trata de un fenómeno de transferencia de las competencias, que tradicionalmente pertenecían a los Estados miembros, a agencias supranacionales que generalmente operan fuera de las principales insituciones de la UE (la Comisión, el Parlamento y el Consejo) (Egeberg \& Trondal 2011).

${ }^{4}$ Ésta se sitúa en un cuadro legislativo modificado ad hoc por el Tratado de Amsterdam, en el que la política de empleo deberá subordinarse a la política económica, tal y como se deduce del art. 126.1 (actual 146.1 TFUE) (Biagi 1998, 2000). En efecto, las recomendaciones hechas a los Estados miembros, previstas en el art. 128.4 del Tratado, tienen efecto eficaz sobre la acción de los gobiernos que no puede ser medido en términos de coacción, sino "desde el punto de vista de influencia indirecta en las actuaciones de los Estados miembros" (Hernández 2012:11). Una recomendación, aunque no es garantía suficiente para que un gobierno en particular acepte las orientaciones comunitarias, supone una importante sanción política que expone al gobierno frente a la opinión pública y a la especulación financiera.

${ }^{5}$ El estudio de la metodología de co-acción y funcionamento del sistema político y del expertise en el sistema comunitario ha destacado una especie de comunidad epistémica que, junto con los lobbies industriales y financieros, define en la UE un techno-corporatism (Fischer 1990) que interviene prepotentemente en la concepción, construcción y aprobación de las políticas públicas. En efecto, en la década 2000-2010, con la Estrategia de Lisboa se refuerza el modus operandi de resolución de problemas, marcado por el fortalecimiento de esta particular interacción pública-privada.
} 
Europe has to become -and fast- a more entrepreneurial and innovative society. But this means not only promoting innovation and the use of new technology, it means removing barriers to entrepreneurship: changing fundamental attitudes towards both risk and success, accelerating decision and administrative processes, reforming cost structures (ERT 2000:2).

Es bajo estas premisas que el 23 y 24 de marzo de 2000, con el Consejo Europeo de Lisboa, se da impulso a la revolución de los últimos veinte años, con el objetivo de "convertir a Europa en la economía basada en el conocimiento más competitiva y dinámica del mundo, capaz de crecer económicamente de manera sostenible con más y mejores empleos y con mayor cohesión social" (Consejo, Reprs. Estados miembros reunidos en el Consejo 2000b: 2). Cambios que alteraban cada aspecto micrológico de la vida de las personas y requerían una transformación radical de la economía europea. El título Más y mejores empleos para Europa: desarrollo de una política activa de empleo del Consejo de Lisboa resume esta nueva etapa consistente en la tentativa de crear "como una necesidad urgente" un cuadro instrumental, legislativo y de comportamiento para la medición y control del trabajo vivo, inmaterial, cooperativo; para crear y regular la escasez del conocimiento codificado en las universidades; para la explotación de las investigaciones e la innovación, de todos los saberes y de las relaciones sociales y culturales bajo el poder del capital (Consejo, Reprs. Estados miembros reunidos en el Consejo 2000b). El objetivo: seguir con la ola modernizadora del modelo social europeo, pensando la problemática de la exclusión social en los términos de la inclusión diferencial; las inversiones en las personas, en los términos de competencias y habilidades (formación/educación); innovación y desarrollo (R\&S), implementando las políticas de Sociedad de la Información, acelerando los procesos de reformas estructurales, con el fin de liberalizar y privatizar los servicios y completar la reforma de la gobernanza europea.

\section{La arquitectura y los dispositivos de medición del saber.}

Se refuerzan y amplifican, así, los mecanismos y las formas de división y explotación del trabajo, reconociendo aún más el papel determinante que desempeña la educación y la formación como parte integrante de las políticas económicas y sociales. En los principales Estados miembros de la Unión Europea se intensifica, de este modo, el proceso de movilidad y precarización del trabajo: bajo el paradigma de la empleabilidad se inauguran las políticas activas de empleo, con la formación continua como piedra angular del proceso de precarización del trabajo, de adaptabilidad, flexibilidad y alternancia. Para hacer frente a este cambio continuo y a las exigencias de competencias cada vez más complejas y actualizadas de acuerdo al nuevo sistema de producción en red, el aprendizaje es concebido como experiencia continua y presente a lo largo de la vida de las personas (Lifelong learning): "con el objetivo de mejorar los conocimientos, las competencias y las aptitudes con una perspectiva personal, cívica, social o relacionada con el empleo" (Comisión de las Comunidades Europeas 2001c:10). La Comisión no se ahorra preámbulos y derivas míticas, como en la comunicación Hacer realidad un espacio europeo del aprendizaje permanente, cuando cita un proverbio chino: 
Para un año, sembrad cereales. Para una década, plantad árboles. Para toda la vida, educad y formad a la gente" (Comisión de las Comunidades Europeas 2001c:1)

Se extiende en primer lugar el campo de influencia de lo que se denomina aprendizaje, superando las limitaciones de las instituciones de formación formal, al abarcar el desarrollo de actividades formativas en los contextos laborales (formación no formal), o también en los contextos de la vida cotidiana (formación informal). En esta línea, con el proceso de Copenhague (2002), se iban a profundizar las cuestiones relativas a la Vocational Educational and Training (VET), por medio de la cooperación reforzada europea en materia de educación y formación profesional (cooperación) entre los actores principales, agencias de acreditación, organizaciones formativas públicas y privadas. Las recomendaciones adoptadas en la Declaración de Copenhague delinean los ejes que fundamentan una meta-estructura europea de cualificaciones, de acuerdo con una lógica de la arquitectura del saber que comprende una mayor escala de dispositivos, con la proposición de un Marco único europeo (common framework), actualmente denominado European Qualifications Framework $(E Q F)^{6}$. Al desarrollo de un Marco Europeo de Cualificaciones para el Aprendizaje a lo Largo de la Vida (EQF) se acompaña, entonces, la introducción de marco metodológico común que facilita la transferencia de los créditos de aprendizaje de un sistema de cualificación a otro (European Credit System for Vocational Education and Training - ECVET), con la definición de un Marco de Referencia Europeo de Garantía de Calidad (European Quality Assurance Reference framework for Vocational Education and Training - EQAVET) y de un marco europeo para las competencias clave. Estas prioridades del Consejo y de la Comisión fueron reiteradas en 2004, en el informe provisional conjunto del Consejo y de la Comisión acerca del progreso del programa de trabajo Education and Training 2010, con el fin de añadir elementos de dimensión europea a los dominios apropiados de las competencias clave. Le siguió al estudio internacional PISA 2000 (OECD 2001), el cual también enfatizaba la importancia de la adquisición de competencias más amplias para alcanzar un aprendizaje exitoso.

Las competencias clave representan un paquete multifuncional y transferible de conocimientos, destrezas y actitudes que todos los individuos necesitan para su

6

- Los principios comunes para la validación del aprendizaje formal, no formal e informal. El objetivo es elaborar una serie de principios comunes para garantizar una mayor compatibilidad entre los enfoques de los diferentes países a distintos niveles. Dicho objetivo podrá ser alcanzado mediante la adopción y experimentación de los principios caracterizados por el documento del Consejo europeo.

- Un sistema de transferencia de créditos para la instrucción y la formación profesional. Inspirado por el sistema europeo de transferencia de créditos en la Formación Superior (ECTS), la intención es desarrollar un sistema análogo para el sector de la formación profesional.

- Un marco único para la transparencia de las competencias y las cualificaciones. La intención era reunir en un único formato manejable y más visible los diferentes instrumentos actuales de transparencia tales como el CV Europeo, los suplementos a los certificados, los suplementos a los diplomas, la movilidad Europass y los puntos de referencia nacionales mediante el uso del dispositivo EUROPASS.

- Unas herramientas de matching para promover las informaciones y las orientaciones sobre las oportunidades de carrera en la Unión Europea (PLOTEUS y Euroguidance network). 
realización y desarrollo personal, inclusión y empleo. Éstas deberían haber sido desarrolladas para el final de la enseñanza o formación obligatoria, y deberían actuar como la base para un posterior aprendizaje como parte de un aprendizaje a lo largo de la vida (Comisión de las Comunidades Europeas 2004:7).

Las competencias clave son un prerrequisito para un rendimiento personal adecuado en esta concepción de vida activa, en el trabajo y en el aprendizaje permanente. Una competencia clave es crucial para tres aspectos de esta vida activa:

- Capital cultural: las competencias clave deben permitir a las personas perseguir objetivos personales en la vida, llevados por sus intereses personales, sus aspiraciones y el deseo de continuar aprendiendo a lo largo de la vida;

- Capital social: las competencias clave deberían permitir a todos una participación como ciudadanos activos en la sociedad;

- Capital humano: la capacidad de todas y cada una de las personas de obtener un puesto de trabajo decente en el mercado laboral.

La Comisión, en esta línea, ha ido definiendo e implementando un marco compuesto por ocho dominios de competencias clave que se consideran necesarios para todos/as en la Sociedad del Conocimiento.

Tabla 1: Los ocho dominios de las competencias clave

\begin{tabular}{|c|c|}
\hline COMPETENCIA & DEFINICIÓN \\
\hline $\begin{array}{l}\text { Comunicación en la } \\
\text { lengua materna }\end{array}$ & $\begin{array}{l}\text { Comunicación es la habilidad para expresar e interpretar pensamientos, } \\
\text { sentimientos y hechos tanto de forma oral como escrita (escuchar, hablar, leer y } \\
\text { escribir), y para interactuar lingüísticamente de forma apropiada en una amplia } \\
\text { gama de contextos sociales y culturales-educación y formación, trabajo, hogar y } \\
\text { ocio. }\end{array}$ \\
\hline $\begin{array}{l}\text { Comunicación en una } \\
\text { lengua extranjera }\end{array}$ & $\begin{array}{l}\text { La comunicación en lenguas extranjeras comparte de forma general las principales } \\
\text { dimensiones de las destrezas de comunicación en la lengua materna: está basada } \\
\text { en la habilidad para comprender, expresar e interpretar pensamientos, } \\
\text { sentimientos y hechos tanto de forma oral como escrita (escuchar, hablar, leer y } \\
\text { escribir) en una gama apropiada de contextos sociales -trabajo, hogar, ocio, } \\
\text { educación y formación- de acuerdo con los deseos y necesidades de cada uno. }\end{array}$ \\
\hline Competencia digital & $\begin{array}{l}\text { La competencia digital implica el uso confiado y crítico de los medios electrónicos } \\
\text { para el trabajo, ocio y comunicación. Estas competencias están relacionadas con } \\
\text { el pensamiento lógico y crítico, con destrezas para el manejo de información de } \\
\text { alto nivel, y con el desarrollo eficaz de las destrezas comunicativas. En el nivel } \\
\text { más básico, las destrezas de TIC comprenden el uso de tecnologías multimedia } \\
\text { para recuperar, evaluar, almacenar, producir, presentar e intercambiar información, } \\
\text { y para comunicar y participar en foros a través de Internet. }\end{array}$ \\
\hline Aprender a aprender & $\begin{array}{l}\text { Aprender a aprender' comprende la disposición y habilidad para organizar y regular } \\
\text { el propio aprendizaje, tanto individualmente como en grupos. Incluye la habilidad } \\
\text { de organizar el tiempo propio de forma efectiva, de resolver problemas, de adquirir, } \\
\text { procesar, evaluar y asimilar conocimientos nuevos, y de ser capaz de aplicar } \\
\text { nuevos conocimientos en una variedad de contextos - en el hogar, en el trabajo, } \\
\text { en la educación y en la formación. }\end{array}$ \\
\hline $\begin{array}{l}\text { Competencias } \\
\text { interpersonales y } \\
\text { cívicas }\end{array}$ & $\begin{array}{l}\text { Las competencias interpersonales comprenden todo tipo de comportamientos que } \\
\text { un individuo debe dominar para ser capaz de participar de forma eficiente y } \\
\text { constructiva en la vida social, y para poder resolver conflictos cuando sea } \\
\text { necesario. Las destrezas interpersonales son necesarias para que haya una } \\
\text { interacción efectiva individualizada o en grupos, y son empleadas tanto en el } \\
\text { ámbito público como en el privado. }\end{array}$ \\
\hline Espíritu emprendedor & $\begin{array}{l}\text { El espíritu emprendedor tiene un componente activo y otro pasivo: comprende } \\
\text { tanto la capacidad para inducir cambios como la habilidad para acoger, apoyar y } \\
\text { adaptarse a los cambios debidos a factores externos. El espíritu emprendedor } \\
\text { implica ser responsable de las acciones propias, ya sean positivas o negativas, el } \\
\text { desarrollo de una visión estratégica, marcar y cumplir objetivos y estar motivado } \\
\text { para triunfar. }\end{array}$ \\
\hline Expresión cultural & $\begin{array}{l}\text { La 'expresión cultural' comprende una apreciación de la importancia de la } \\
\text { expresión de ideas de forma creativa en una serie de medios de expresión, } \\
\text { incluyendo la música, expresión corporal, literatura y artes plásticas. }\end{array}$ \\
\hline
\end{tabular}

Fuente: (Comisión de las Comunidades Europeas 2004:8-9) 
Sin embargo, en la arquitectura del saber promovida por la Comisión, es la transferibilidad de las competencias clave y su aplicabilidad en distintas situaciones y contextos el objetivo estratégico, por eso la medición del grado de dominio de la mayoría de estas competencias es su gran reto. Las herramientas de medición existentes, que la OCDE fue estableciendo a gran escala (como son PISA, PIRLS, TIMSS o ALL), indican los niveles de dominio con respecto a la alfabetización y a la alfabetización numérica. El Marco Común Europeo de Referencia para las Lenguas del Consejo de Europa describe niveles de dominio en lenguas extranjeras, y se ha investigado en la medición de la competencia aprender a aprender. Asimismo, hay una serie de herramientas nacionales de medición para identificar los niveles de dominio apropiados de las destrezas básicas, con el fin de guiar la adopción de políticas en varios niveles. Mientras que sólo algunas de las competencias clave son medibles, el marco de referencia ayuda a colocar éstas en un contexto de igual importancia a las competencias genéricas y transversales, que son más difíciles de medir (Comisión de las Comunidades Europeas 2004).

\section{El Lifelong Learning y las acciones para la movilidad.}

Lifelong learning is no longer just one aspect of education and training; it must become the guiding principle for provision and participation across the full continuum of learning contexts. The coming decade must see the implemention of this vision. All those living in Europe, without exception, should have equal opportunities to adjust to the demands of social and economic change and to participate actively in the shaping of Europe's future (Comisión de las Comunidades Europeas 2000b:3).

El Consejo Europeo de 2006, con la finalidad de actuar para conseguir los objetivos establecidos en la estrategia para el desarrollo de la educación y formación profesional en Barcelona y Copenhague, definió un programa general para promover la movilidad dentro de la estrategia general del aprendizaje permanente. El programa de aprendizaje Lifelong Learning Programme (LLP) se configuró así como el principal instrumento de financiación comunitaria en el sector de la instrucción, tanto en las actividades formativas a lo largo de la vida, como en los programas de movilidad en Europa. El LLP agrupa todas las iniciativas de cooperación europea en el ámbito de la educación y formación desde el 2007 al 2013; todas las medidas concretas implementadas por la UE para realizar los objetivos establecidos en Copenhague, ampliando la línea de actuación no sólo a los estudiantes sino también a los docentes, formadores y a todos los perfiles involucrados en las actividades formativas. En particular, se propone promover los intercambios, la cooperación y la movilidad entre los sistemas de educación y formación de modo que se implemente el mercado de las competencias y habilidades; y estos se transformen en puntos de referencia a nivel mundial. Han sido puestos en marcha, en coherencia con esta visión, cuatro sub-programas que financian varios proyectos según los niveles de educación y formación: Comenius, que está destinado al ámbito de la escuela primaria y secundaria; Erasmus, dirigido al ámbito de la educación superior; Leonardo da Vinci, que abarca la educación y formación profesional; y, finalmente, el Grundtvig, que contiene las iniciativas para promover la educación de los adultos. En la lógica de integración entre el Proceso de Bolonia y el Proceso de Copenhague, por lo que concierne a la 
educación y formación profesional en la cooperación entre los Estados miembros, la Comisión decidió financiar las líneas de acción que están dirigidas primariamente a predisponer y/o a aplicar las recomendaciones europeas sobre European Qualifications Framework for lifelong learning (EQF), soportada por iniciativas para la transparencia de las calificaciones (Europass), la transferencia y el reconocimiento de créditos (el European Credit Transfer and Accumulation System for Higher Education -ECTS- y el European Credit System for Vocational Education and Training -ECVET-), y las garantías de calidad (European association for quality assurance in higher education -ENQAy el European Network for Quality Assurance in Vocational Education and Training -ENQA).

\section{La constitución del EEES: la mecánica competencial para la explotación del conocimiento}

Para resolver los desajustes persistentes que existen entre las cualificaciones de los licenciados y las necesidades del mercado de trabajo, los programas universitarios deberían estructurarse de manera que se mejore directamente la empleabilidad de los licenciados y se ofrezca un amplio apoyo a la mano de obra de modo más general. Las universidades deben ofrecer planes de estudio, métodos docentes y programas de formación o readiestramiento innovadores que, a las capacidades más propias de la disciplina, sumen otras de carácter más amplio relacionadas con el empleo (Comisión de las Comunidades Europeas 2006b:7).

Los objetivos de la estrategia de Lisboa han provocado el diseño de una serie de reformas orientadas a la construcción del Espacio Europeo de Educación Superior (EEES), con el fin de implementar la movilidad de estudiantes y profesionales para flexibilizar siempre más el mercado laboral, al tiempo que con la Declaración de Bolonia se daba la vía a una renovación de los planes didácticos de toda la enseñanza universitaria. De modo que "esta política es coherente con el discurso de la OCDE de liberalización de la enseñanza. (...) es previsible que la educación, como otros servicios públicos, terminen cediendo su actividad al mercado y la comercialización internacional" (Sierra Caballero 2006:100). En esta dirección, la estrategia de Lisboa fue revisada y ratificada en Barcelona (2002), poniendo de relieve la necesidad de realizar una actuación prioritaria bajo el eslogan de "más y mejores puestos de trabajo". El tercer punto del plano de actuación se centra en "Una economía competitiva basada en el conocimiento" y se detalla en el Programa de trabajo para 2010, con el cual se quiere vincular de forma indisoluble los sistemas de educación con los de formación. Se insiste sobre la necesidad de retomar con más fuerza el Proceso de Bolonia (1999) e introducir instrumentos que garanticen la transparencia de los diplomas y cualificaciones (Sistema Europeo de Transferencia de Créditos -ETCS-, suplementos a los diplomas y certificados, Currículum Vital europeo). Los elementos principales que configuran el nuevo escenario del EEES (crédito europeo, currículos estructurados en dos niveles, acreditación para asegurar la calidad y transparencia mediante el suplemento europeo al título), se subordinan al objetivo más general de promover la movilidad, el reconocimiento mutuo de los estudios entre instituciones y países y la propia competitividad del mercado laboral.

El proceso de Bolonia establece una lógica de sumisión al mercado y de competencia extrema entre las Universidades. Como suele ocurrir en estos casos, algunos centros de enseñanza superior se beneficiarán enormemente y otros empeorarán 
considerablemente su situación. [...] Teniendo en cuenta la importancia que muchas universidades tienen como motores del desarrollo regional, Bolonia terminará contribuyendo a incrementar los desequilibrios territoriales (Uncetabarrenechea 2009:145).

Tabla 2: The Bologna Process. From Sorbonne to Leuven/Louvain-la-Neuve, 1998-2009

\begin{tabular}{|c|c|c|c|c|c|c|}
\hline $\begin{array}{l}\text { Mobility of } \\
\text { students and } \\
\text { teachers }\end{array}$ & $\begin{array}{l}\text { Mobility of } \\
\text { students, } \\
\text { teachers, } \\
\text { researchers and } \\
\text { administrative } \\
\text { staff }\end{array}$ & $\begin{array}{l}\text { Social } \\
\text { dimension of } \\
\text { mobility }\end{array}$ & $\begin{array}{l}\text { Portability of } \\
\text { loans and } \\
\text { grants } \\
\text { Improvement } \\
\text { of mobility } \\
\text { data }\end{array}$ & $\begin{array}{l}\text { Attention to } \\
\text { visa and } \\
\text { work permits }\end{array}$ & $\begin{array}{l}\text { Challenges } \\
\text { of visa and } \\
\text { work permits, } \\
\text { pension } \\
\text { systems and } \\
\text { recognition }\end{array}$ & $\begin{array}{l}\text { Benchmark of } \\
20 \% \text { by2020 for } \\
\text { student } \\
\text { mobility }\end{array}$ \\
\hline $\begin{array}{l}\text { A common } \\
\text { two-cycle } \\
\text { degree } \\
\text { system }\end{array}$ & $\begin{array}{l}\text { Easily readable } \\
\text { and comparable } \\
\text { degrees }\end{array}$ & $\begin{array}{l}\text { Fair } \\
\text { recognition } \\
\text { Development } \\
\text { of recognised } \\
\text { Joint degrees }\end{array}$ & $\begin{array}{l}\text { Inclusion of } \\
\text { doctoral level } \\
\text { as third cycle }\end{array}$ & $\begin{array}{l}\text { QF-EHEA } \\
\text { adopted } \\
\text { National } \\
\text { Qualifications } \\
\text { Frameworks } \\
\text { launched }\end{array}$ & $\begin{array}{l}\text { National } \\
\text { Qualifications } \\
\text { Frameworks } \\
\text { by } 2010\end{array}$ & $\begin{array}{l}\text { National } \\
\text { Qualifications } \\
\text { Frameworks by } \\
2012\end{array}$ \\
\hline & & $\begin{array}{l}\text { Social } \\
\text { dimension }\end{array}$ & $\begin{array}{l}\text { Equal } \\
\text { access }\end{array}$ & $\begin{array}{l}\text { Reinforcement } \\
\text { of the social } \\
\text { dimension }\end{array}$ & $\begin{array}{l}\text { Commitment } \\
\text { to produce } \\
\text { national } \\
\text { action plans } \\
\text { with effective } \\
\text { monitoring }\end{array}$ & $\begin{array}{l}\text { National } \\
\text { targets for the } \\
\text { social } \\
\text { dimension to } \\
\text { be measured } \\
\text { by } 2020\end{array}$ \\
\hline & & $\begin{array}{l}\text { Lifelong } \\
\text { learning } \\
\text { (LLL) }\end{array}$ & $\begin{array}{l}\text { Alignment of } \\
\text { national LLL } \\
\text { policies } \\
\text { Recognition } \\
\text { of Prior } \\
\text { Learning } \\
\text { (RPL) }\end{array}$ & $\begin{array}{l}\text { Flexible } \\
\text { learning } \\
\text { paths in } \\
\text { higher } \\
\text { education }\end{array}$ & $\begin{array}{l}\text { Role of } \\
\text { higher } \\
\text { education in } \\
\text { LLL } \\
\text { Partnerships } \\
\text { to improve } \\
\text { employability }\end{array}$ & $\begin{array}{l}\text { LLL as a public } \\
\text { responsibility } \\
\text { requiring } \\
\text { strong } \\
\text { partnerships } \\
\text { Call to work on } \\
\text { employability }\end{array}$ \\
\hline $\begin{array}{l}\text { Use of } \\
\text { credits }\end{array}$ & $\begin{array}{l}\text { A system of } \\
\text { credits (ECTS) }\end{array}$ & $\begin{array}{l}\text { ECTS and } \\
\text { Diploma } \\
\text { Supplement } \\
\text { (DS) }\end{array}$ & $\begin{array}{l}\text { ECTS for } \\
\text { credit } \\
\text { accumulation }\end{array}$ & & $\begin{array}{l}\text { Need for } \\
\text { coherent use } \\
\text { of tools and } \\
\text { recognition } \\
\text { practices }\end{array}$ & $\begin{array}{l}\text { Continuing } \\
\text { implementation } \\
\text { of Bologna } \\
\text { tools }\end{array}$ \\
\hline & $\begin{array}{l}\text { European } \\
\text { cooperation in } \\
\text { quality } \\
\text { assurance }\end{array}$ & $\begin{array}{l}\text { Cooperation } \\
\text { between } \\
\text { quality } \\
\text { assurance } \\
\text { and } \\
\text { recognition } \\
\text { professionals }\end{array}$ & $\begin{array}{l}\text { Quality } \\
\text { assurance at } \\
\text { institutional, } \\
\text { national and } \\
\text { European } \\
\text { level }\end{array}$ & $\begin{array}{l}\text { European } \\
\text { Standards } \\
\text { and } \\
\text { Guidelines } \\
\text { for quality } \\
\text { assurance } \\
\text { adopted }\end{array}$ & $\begin{array}{l}\text { Creation of } \\
\text { the European } \\
\text { Quality } \\
\text { Assurance } \\
\text { Register } \\
\text { (EQAR) }\end{array}$ & $\begin{array}{l}\text { Quality as an } \\
\text { overarching } \\
\text { focus for EHEA }\end{array}$ \\
\hline $\begin{array}{l}\text { Europe of } \\
\text { Knowledge }\end{array}$ & $\begin{array}{l}\text { European } \\
\text { dimensions in } \\
\text { higher education }\end{array}$ & $\begin{array}{l}\text { Attractiveness } \\
\text { of the } \\
\text { European } \\
\text { Higher } \\
\text { Education } \\
\text { Area }\end{array}$ & $\begin{array}{l}\text { Links } \\
\text { between } \\
\text { higher } \\
\text { education } \\
\text { and research } \\
\text { areas }\end{array}$ & $\begin{array}{l}\text { International } \\
\text { cooperation } \\
\text { on the basis } \\
\text { of values and } \\
\text { sustainable } \\
\text { development }\end{array}$ & $\begin{array}{l}\text { Strategy to } \\
\text { improve the } \\
\text { global } \\
\text { dimension of } \\
\text { the Bologna } \\
\text { process } \\
\text { adopted }\end{array}$ & $\begin{array}{l}\text { Enhance global } \\
\text { policy dialogue } \\
\text { through } \\
\text { Bologna Policy } \\
\text { Fora }\end{array}$ \\
\hline $\begin{array}{c}1998 \\
\text { Sorbonne } \\
\text { Declaration }\end{array}$ & $\begin{array}{l}1999 \text { Bologna } \\
\text { Declaration }\end{array}$ & 2001 Prague & 2003 Berlin & 2005 Bergen & $\begin{array}{l}2007 \\
\text { London }\end{array}$ & $\begin{array}{c}2009 \text { Leuven/ } \\
\text { Louvain-la- } \\
\text { Neuve }\end{array}$ \\
\hline
\end{tabular}

Fuente: (Eurydice 2012); Elaboración del autor

Plantear una educación lo más cercana posible a las exigencias de las empresas y del mercado, esto es, una educación que sea funcional a relaciones sociales encaminadas a la plena movilidad, flexibilidad, adaptabilidad y espíritu empresarial determinando, de este modo, el sentido de la cualificación de la fuerza trabajo y el sostenimiento del nuevo Capitalismo 
Cognitivo $^{7}$. La escuela y las universidades tienen que responder a las crecientes inversiones del capital en productos cognitivos. Hablamos del crecimiento de inversiones en investigación, en $I+D$, en enseñanza, en informática, telemática, nuevas fuentes de energía y nuevos materiales, en medicina; vistos no sólo por su contribución cuantitativa al crecimiento en sus sectores específicos, sino por el enorme peso que adquieren en el aumento de la productividad general.

Tabla 3: Los cambios que se dan de forma convergente entre educación y nueva economía después del Consejo Europeo de Lisboa

\begin{tabular}{|c|c|c|}
\hline $\begin{array}{l}\text { Modelo } \\
\text { Económico }\end{array}$ & Modelo educativo & Modelo organizacional \\
\hline $\begin{array}{l}\text { Innovación } \\
\text { tecnológica }\end{array}$ & $\begin{array}{l}\text { - } \quad \text { Creación de conocimientos } \\
\text { - } \quad \text { Integración Universidad - Empresa }\end{array}$ & $\begin{array}{l}\text { - Universidades innovadoras } \\
\text { - } \quad \text { Universidades de research } \\
\text { - } \quad \text { Parques tecnológicos } \\
\text { - Incubadoras de empresas }\end{array}$ \\
\hline Escala global & $\begin{array}{l}\text { - } \quad \text { Currículo internacional } \\
\text { - } \quad \text { Libre movilidad de estudiantes, docentes y } \\
\text { certificaciones }\end{array}$ & $\begin{array}{l}\text { - Universidades globales } \\
\text { - } \quad \text { Universidades en redes }\end{array}$ \\
\hline Digitalización & $\begin{array}{ll}\text { - } & \text { Educación virtual } \\
\text { - } & \text { Autoaprendizaje en modelos de simulación }\end{array}$ & $\begin{array}{l}\text { - Universidades virtuales } \\
\text { - } \quad \text { Universidades multimodales }\end{array}$ \\
\hline Especialización & - Ciclos de alta especialización & - Universidades de postgrados \\
\hline $\begin{array}{l}\text { Complejidad } \\
\text { productiva }\end{array}$ & $\begin{array}{l}\text { - Educación permanente } \\
\text { - Educación "just in time" }\end{array}$ & - Universidades coorporativas \\
\hline
\end{tabular}

Fuente: (Rama 2008); Elaboración del autor.

En otras palabras, "las empresas deben indicar a las instituciones educativas las necesidades globales del mercado, qué competencias exige la formación productiva y cómo -en fin- adaptarse al cambio social" (Sierra Caballero 2006, p.101). Ahora bien, la renovación de las enseñanzas universitarias no pasa sólo por un cambio estructural de las titulaciones con base en las demandas del mercado laboral, sino más bien en un nuevo diseño didáctico y curricular centrado en los resultados de aprendizaje, expresados en términos de competencias.

Seleccionar las competencias a desarrollar; analizar cada competencia e identificar los componentes, habilidades, actitudes y conocimientos, seleccionando los que deban ser trabajados en cada módulo; identificar las asignaturas y otras intervenciones expresamente diseñadas para tal finalidad; formular resultados de aprendizaje que permitan identificar la concreción de las competencias que se les propone desarrollar a los alumnos; planificar el desarrollo de los objetivos eligiendo estrategias de aprendizaje y enseñanza, y diseñando el sistema de evaluación; distribuir el tiempo de trabajo de los estudiantes, según el número de ECTS y horas correspondientes, entre los diferentes módulos, para lo que es fundamental valorar la importancia relativa dentro del proyecto, de las competencias que se están trabajando en cada periodo para que esta distribución sea coherente con el mismo" (Yániz Álvarez de Eulat 2006:25).

\footnotetext{
${ }^{7}$ Con este concepto se designa el impulso adquirido por una economía fundada en la difusión del saber y en la cual la producción de conocimiento deviene la oportunidad principal de valorización del capital. En esta transición (del capitalismo industrial al capitalismo cognitivo) la parte del capital inmaterial e intelectual, definida por la proporción de trabajadores del conocimiento ("knowledge workers) y de las actividades con alta intensidad en saber (servicios informáticos, I+D, enseñanza, formación, sanidad, multimedia, software,...) es cada vez más la variable clave del crecimiento y de la competitividad de las naciones (Vercellone 2002, p.14).
} 
Con el proceso de Bolonia se impone así la adopción de un modelo competencia basado en la larga tradición técnico-administrativista (Bolívar 2008), que hace de la planificación y del diseño currículares la base para la oferta en el marcado del EEES. Así por ejemplo, el proyecto Tuning Educational Structures in Europe (González \& Wagenaar 2003; 2006; Bolívar \& Pallás 2007) financiado por el programa comunitario Tempus, empieza en el año 2000, por la cooperación de diferentes universidades europeas, con la idea de sintonizar y armonizar los estudios superiores entre países europeos y favorecer el proceso de Bolonia. La metodología de acción propuesta vincula las competencias para determinar los logros en el aprendizaje con los créditos ECTS (European Credit Transfer System), definidos en términos temporales: "el tiempo que las competencias pueden servir para expresar la comparabilidad y transparencia entre titulaciones" (González and Wagenaar 2006). Se establece así la línea de acción común en la planificación curricular: son los perfiles profesionales a determinar las competencias y los créditos $y$, consecuentemente, la selección de los conocimientos y la planificación de la metodología y de los contenidos. Los objetivos, a nivel general o específico, deben expresarse en términos de competencias que capacitan para un determinado ejercicio profesional en el caso del primer ciclo de estudios, o para la especialización e investigación en el caso del segundo ciclo o de los programas de postgrado.

\section{Gráfico 1: Learning outcomes and competences in study programmes}

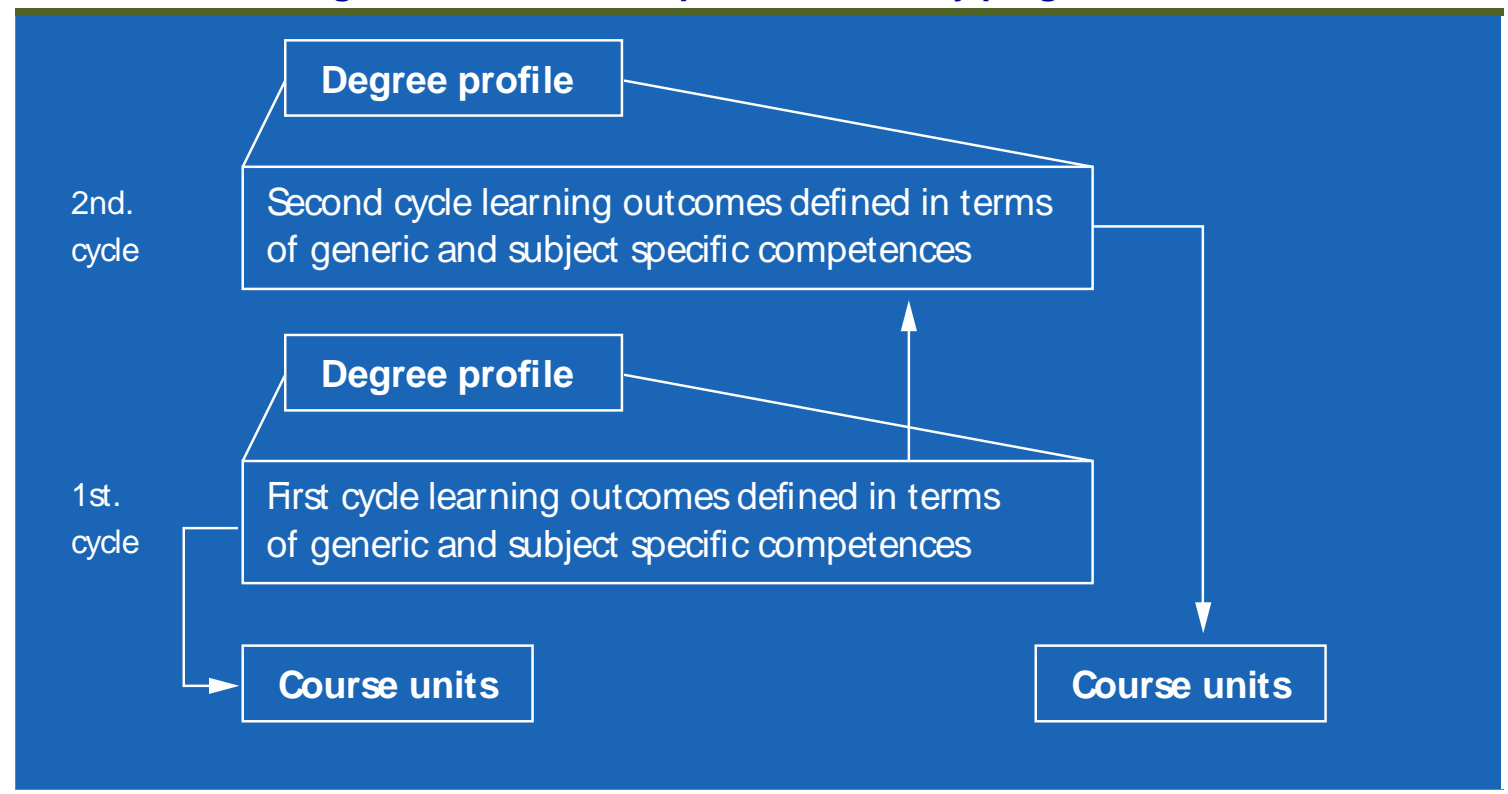

Fuente: (González and Wagenaar 2006:20); Elaboración del autor.

El diseño de una titulación se establece determinando y concretando los objetivos expresados en capacidades o competencias (generales y específicas), que -a su vez- deben condicionar la selección de los contenidos más apropiados para cada objetivo o competencia particular. Los objetivos se distinguen definiendo las competencias generales, por lo que concierne al logro de la capacidad de análisis y síntesis, la capacidad para el trabajo conjunto, aprender a aprender, resolución de problemas, la capacidad para el liderazgo, las habilidades de organización y planificación. Esto es, son aquellas habilidades y capacidades que se pueden transferir en varias situaciones más 
allá de las específicas de los planes de estudio. Además de estas competencias generales, en cada titulación se tienen que definir los objetivos específicos en términos de competencias específicas, o sea los conocimientos y las habilidades ligadas al área de estudios y que hacen referencia a los métodos y técnicas propias y pertinentes del campo disciplinar en concreto.

Tabla 5: Competencias Generales y Específicas de los planes de estudio superiores

\begin{tabular}{|c|c|c|}
\hline $\begin{array}{c}\text { Competencias } \\
\text { básicas }\end{array}$ & $-\quad \begin{array}{l}\text { Conocer y comprender (conocimiento teórico de un campo académico, la } \\
\text { capacidad de conocerlo y entenderlo) } \\
\text { Conocer cómo actuar (aplicación práctica y operativa del conocimiento a } \\
\text { situaciones determinadas) } \\
\text { Conocer cómo ser (valores interpersonales en un contexto social). }\end{array}$ \\
\hline $\begin{array}{c}\text { Competencias } \\
\text { generales o } \\
\text { clave }\end{array}$ & $-\quad \begin{array}{l}\text { Habilidades y destrezas transferibles y comunes a cualquier titulación, } \\
\text { subdivididas en competencias instrumentales, interpersonales y sistémicas. }\end{array}$ \\
\hline $\begin{array}{c}\text { Competencias } \\
\text { específicas }\end{array}$ & $-\quad \begin{array}{l}\text { Conocimiento teórico, práctico y/o experimental. } \\
\text { Habilidades específicas del área. }\end{array}$ \\
\hline
\end{tabular}

Fuente: (Bolívar 2008; González and Wagenaar 2006); Elaboración del autor.

En el proceso de construcción de un Espacio Europeo de Educación Superior, son los perfiles académicos y profesionales los que, en primer lugar, determinan los objetivos y los contenidos en razón de su contribución instrumental al desarrollo de ciertas competencias. La construcción de un plan de estudios basado en este enfoque, en efecto, es estratégico para la integración de la formación profesional en la Educación Superior, subordinando así la enseñanza universitaria al mercado laboral flexible: formar individuos que posean activos competenciales para adaptarse a un futuro laboral cambiante, en un aprendizaje a lo largo de la vida.

Gráfico 2: Learning outcomes: different pathways leading to comparable results

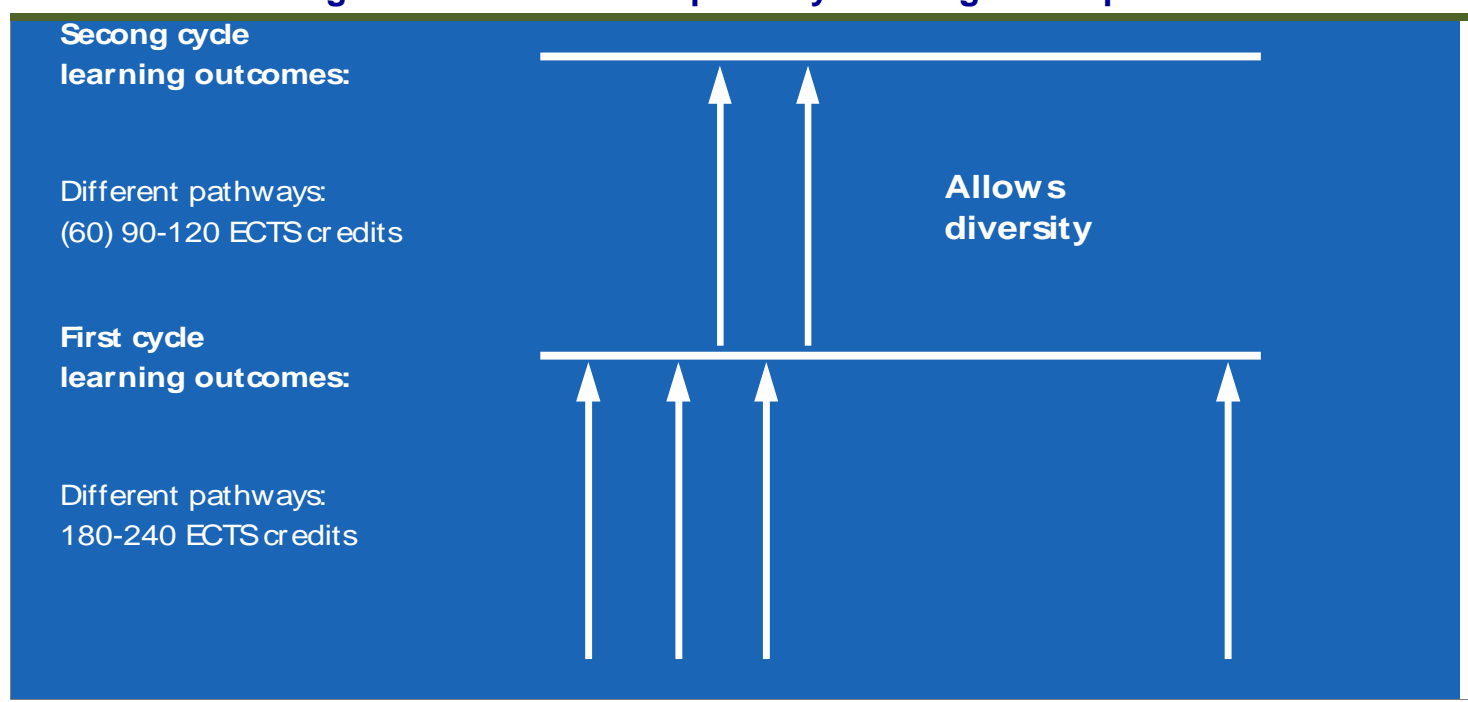

Fuente: (González and Wagenaar 2006:18); Elaboración del autor.

La estrategia del techno-corporatism de crear un espacio universitario europeo, reforzada con la estrategia de Lisboa y con el Proceso de Bolonia, aunque aparente y políticamente se propone como defensiva, o sea pretende preparar la estructura para competir en la transnacionalización del mercado universitario, 
es en realidad parte estratégica de la ofensiva de las corporaciones, en tanto que construye los principales ejes en el conjunto de los dispositivos de la división internacional del trabajo y del conocimiento.

Con cuatro mil instituciones, más de diecisiete millones de alumnos y alrededor de un millón y medio de efectivos - de los que cuatrocientos treinta y cinco mil son investigadores-, las universidades europeas poseen un potencial enorme, pero este potencial no está plenamente aprovechado ni utilizado de forma eficaz para apoyar el impulso de Europa hacia un mayor crecimiento y un mayor número de puestos de trabajo" (Comisión de las Comunidades Europeas 2006a, p.3).

La Comisión Europea, en la comunicación Cumplir la agenda de modernización para las universidades: educación, investigación e innovación, es clara en sus propósitos de segmentar las instituciones de educación superior (en términos de excelencias, por un lado; instituciones profesionalizantes, instituciones para la investigación en determinadas áreas o sectores y polos tecnológicos, por otro) para explotar el conocimiento y las habilidades; y de especificar sus actividades en función de los mismos, determinando un cuadro estructural que permita una inclusión diferencial del capital humano en el mercado del trabajo y fortalecer así la división del trabajo y del saber.

Todas las instituciones comparten ciertos valores y tareas comunes, pero no todas requieren el mismo equilibrio entre educación e investigación, el mismo planteamiento de la investigación y la formación investigadora, ni la misma combinación de servicios y disciplinas académicas. La investigación debe seguir siendo una tarea clave de los sistemas en su conjunto, pero no necesariamente de todas las instituciones (Comisión de las Comunidades Europeas 2006b: 4-5).

Estos cambios estructurales se enfocan a crear un sistema articulado de disposición, división y control que abarca, por un lado, las instituciones de investigación transnacionales con mayor evaluación y ranking; y, por otro, redes de universidades nacionales y metropolitanas caracterizadas por la demanda de educación técnica de menor duración. Otro punto nodal de esta estrategia es la movilidad geográfica e intersectorial. Tal y como se remarca en el Séptimo Programa Marco de Investigación y Desarrollo Tecnológico 20072013 (2006), el presupuesto en términos de inversiones para la investigación en el EEES está fuertemente ligado a las medidas para la cooperación (56\%), mientras que a las acciones directas para la investigación solo se destina un $0,4 \%$ del total.

Gráfico 3: FP7 — Implementation 2011 by themes (million EUR)

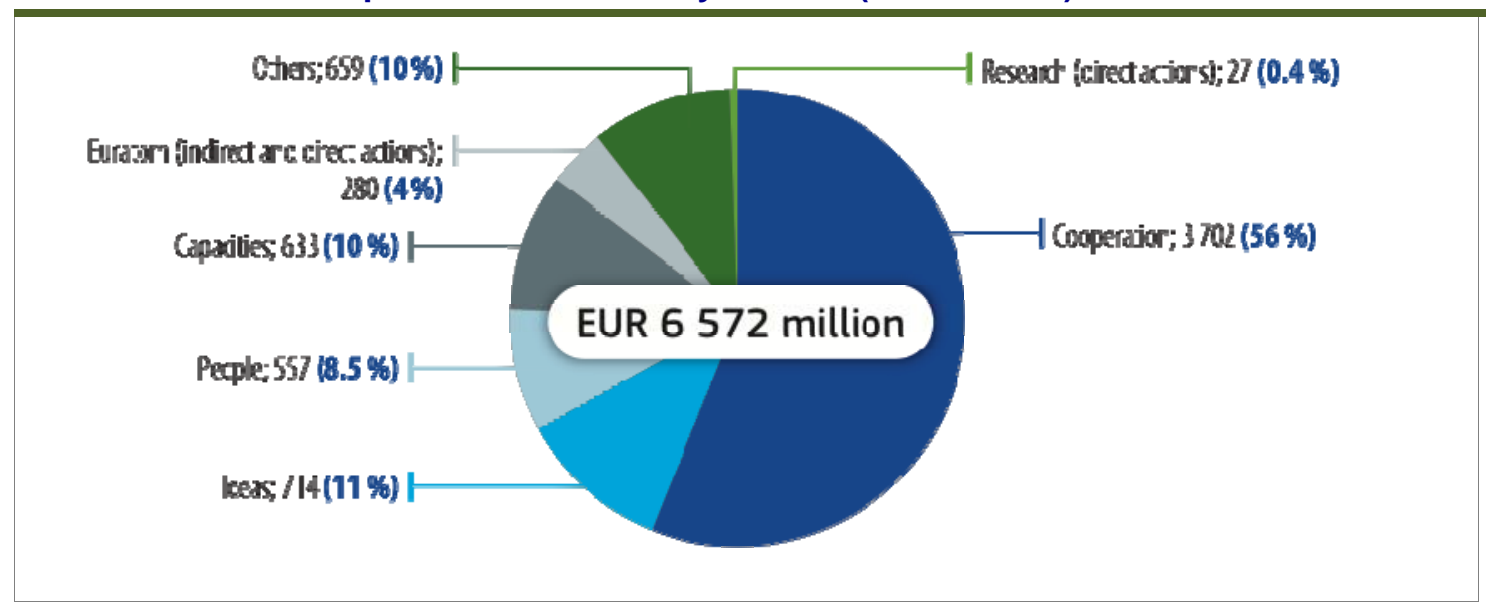

Fuente: (Comisión de las Comunidades Europeas 2012) 
Así que aquel carácter "voluntario" (tal y como define el parlamento europeo) de la labor de investigación, que tendría que suponer la libertad en investigación, en realidad es parte de un discurso más amplio del parlamento; discurso que vincula estrechamente este derecho a un código de conducta (la flexibilidad y la movilidad) que procura a la construcción del mercado laboral europeo de los investigadores:

Los principios generales recogidos en la Carta europea de los investigadores y el Código de conducta para su contratación podrían ayudar en la construcción de un verdadero mercado laboral europeo de los investigadores, al tiempo que respetarían su carácter voluntario. Además, debe desarrollarse y potenciarse la excelencia de las instituciones de investigación y universidades europeas" (Parlamento Europeo and Consejo, Reprs. Estados miembros reunidos en el Consejo 2006: 412/2).

Son las redes de cooperación a ser incentivadas y a imponerse, así, como modelo organizativo y funcional para la I+D y como dispositivos de división del trabajo en el EEES. De este modo la cooperación internacional se incorpora en los procesos de generación de conocimientos, desarrollo de tecnologías y de innovación, hasta convertirse en un componente intrínseco de estos procesos de trabajo. El techno-corporatism europeo interviene así en la mecánica de producción y explotación del conocimiento determinando las áreas en las cuales implementar las I+D.

Gráfico y tabla 4: FP7 — Implementation by research theme (million EUR)

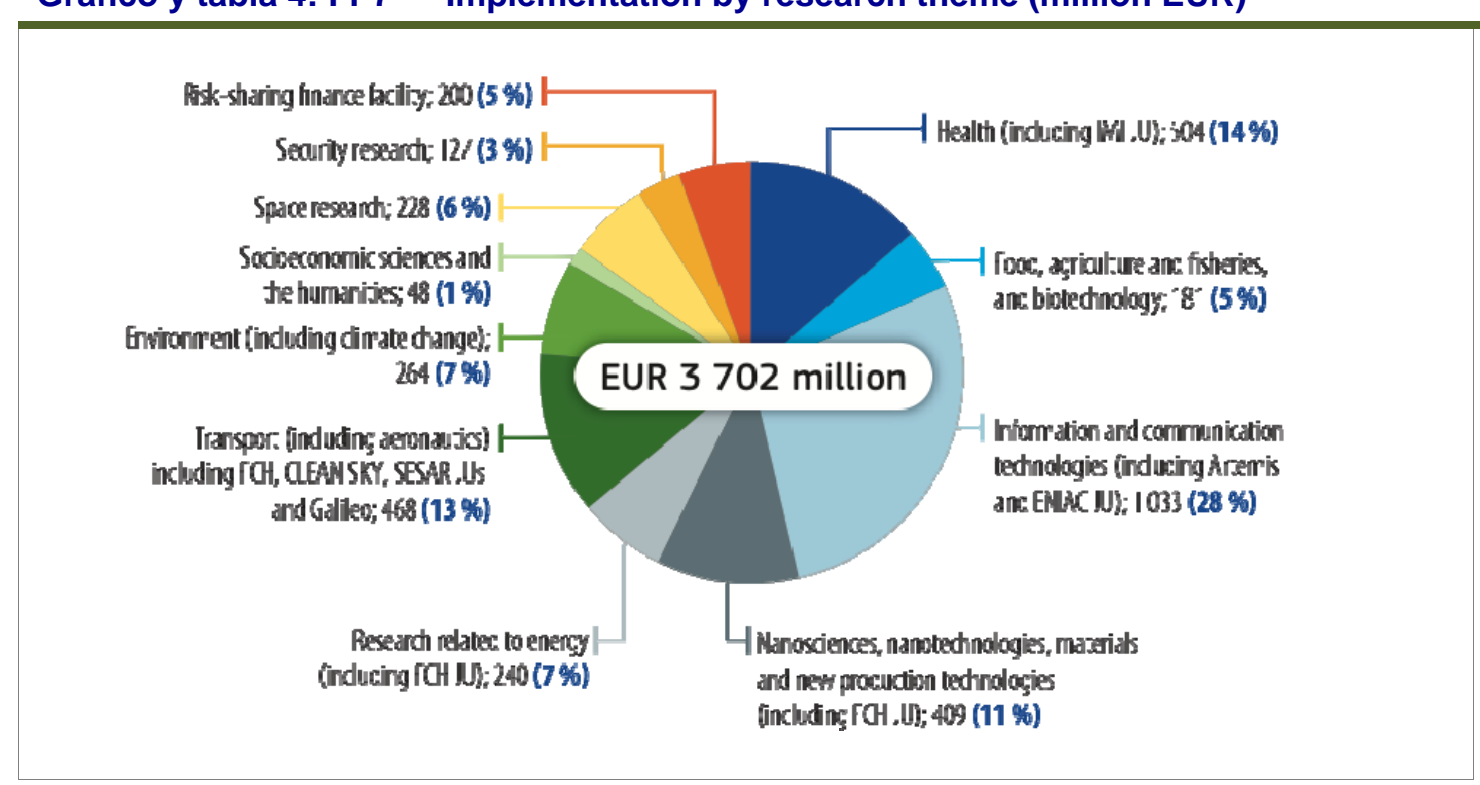

Fuente: (Comisión de las Comunidades Europeas 2012)

Con el Séptimo Programa Marco de Investigación y Desarrollo Tecnológico se definen así las líneas estratégicas de la investigación en el EEES, determinando el sector de las high skill en la división del conocimiento y del trabajo; no solo en el código de conducta (flexibilidad y movilidad laboral) sino también los dispositivos de selección del saber estratégico para el desarrollo industrial y financiero. 


\section{La revisión del EEE y de la Estrategia de Lisboa.}

La Estrategia de Lisboa incorporó la Estrategia Europea de Empleo (EEE), como un elemento más de la misma, lo cual es absolutamente evidente a partir de la evaluación del año 2002 (Cabeza Pereiro and Ballester Pastor 2012).

En el Consejo Europeo de Lisboa, la Unión Europea definió una estrategia global que tiene como objetivo el crecimiento económico a largo plazo, el pleno empleo, la cohesión social y el desarrollo sostenible en una sociedad basada en el conocimiento. En la actualidad, se reconoce ampliamente que debería considerarse a la EEE como un instrumento clave para sostener la Estrategia de Lisboa en la UE ampliada, con lo que la EEE contribuirá también a la cohesión económica y social (Comisión de las Comunidades Europeas 2003:4).

En el Balance de cinco años de aplicación de la Estrategia Europea de Empleo (2002a), la Comisión subraya positivamente su trabajo $^{8}$ en terminos de generación de empleo, aunque no verifica las determinantes cualitativas del empleo activado (tipología de empleo activado en hight, medium or low skills) y tampoco se pone de acuerdo en "determinar en qué medida este mejor comportamiento del mercado de trabajo de la Unión en el curso de los últimos cinco años puede atribuirse a la aplicación de la EEE o en qué medida es imputable al crecimiento económico"(Comisión de las Comunidades Europeas 2002a:2). En todo caso, la calidad del empleo se presenta como una posición propagandística de la UE, ya que nunca ha establecido parámetros concretos para determinar a lo que se refiere con el termino calidad del empleo (por tipo y duración de contracto de trabajo, trabajo vocacional, contribuciones a la seguridad social, etc.). Evidentemente porque el primer objetivo de la Comisión sigue siendo el proceso gradual de destrucción del estado de bienestar asociado, o sea emplear indicadores cuantitativos más que en los cualitativos. Se hace siempre más característica una dualidad del trabajo, donde los empleados efectivos crecen en las dos extremidades: el trabajo cognitivo aumenta rápidamente al mismo tiempo que genera mayormente empleos pocos calificados en el comercio y en los servicios a las personas. Se trata, en definitiva, de un proceso centrífugo de repartición mundial de las actividades productivas, determinado por un movimiento de polarización de las energías humanas y exasperado por una diferenciación reiterada que no se refiere solo a las actividades intensivas de conocimiento sino a todas las actividades humanas. Es propiamente fortaleciendo lo que hemos definido como mecanismos de inclusión diferencial que la Comisión plantea el objetivo de aumentar las tasas de ocupación y fomentar un mercado de trabajo más integrador, que permita al acceso al empleo a todos los grupos sociales. En primer lugar, incrementando la empleabilidad de los trabajadores, su capacidad para mantenerse activos, además, a lo largo de toda la vida. En segundo lugar, como se explicita en el capítulo Adaptabilidad: relación compleja entre flexibilidad, seguridad y calidad del empleo (Comisión de las Comunidades Europeas 2002a), siguiendo en la búsqueda de los mecanismos que puedan incrementar la flexibilidad laboral:

La promoción de un entorno empresarial favorable a la creación de empleo constituye una prioridad, así como el equilibrio entre la flexibilidad y la seguridad en el mercado de trabajo (Comisión de las Comunidades Europeas 2002a:20).

\footnotetext{
${ }^{8}$ Se pone en evidencia la creación de más de diez millones de puestos de trabajo desde 1997, se había reducido el paro en cuatro millones de parados y se había incrementado la población activa en cinco millones de personas.
} 
Para fortalecer esta continuidad y con base en las conclusiones de la Comunicación de la Comisión sobre El futuro de la Estrategia Europea de Empleo (EEE). Una estrategia para el pleno empleo y mejores puestos de trabajo para todos (2003), el Consejo ratifica la Decisión relativa a las Directrices para las políticas de empleo de los Estados miembros (2003a) con el objetivo de integrar los principales puntos de la Estrategia de Lisboa en la EEE y aclarar las prioridades políticas de ésta. Las Directrices para el empleo 2003-2005 refuerzan la política del supuesto crecimiento mediante reformas estructurales, interviniendo sobre el sistema de la gobernanza europea en este campo. Se resolda la alianza techno-corporativa introduciendo formas siempre más simplificadas en la metodología decisoria del MAC con el fin de vincular más las políticas económicas y las políticas de empleo. En este proceso, las Orientaciones Generales de Política Económica (OGPE) van a tener un papel central, subordinado definitivamente la política de empleo a las necesidades coorporativas. Es en este cuadro analitico que leemos el informe Facing the Challenge: The Lisbon Strategy for Growth and Employment: Report from the Higher Level Group, coordinado por Win Kok (2004), con el cual, más allá de evidenciar los insuficientes resultados alcanzados y la práctica imposibilidad de alcanzar los objetivos fijados con la Estrategia de Lisboa para 2010, paradójicamente reedita las mismas recetas que llevaron a los resultados insuficientes. El informe en efecto propone continuar con las reformas estructurales por lo que concierne a la despolitización y tecnicización del MAC, mediante su simplificación y subordinación a las OGPE. Con estas premisas, la Comisión exponía al Consejo Europeo la necesidad de un relanzamiento de la Estrategia de Lisboa con la comunicación Trabajando juntos por el crecimiento y el empleo. Relanzamiento de la estrategia de Lisboa (2005a):

Es indispensable reactivar sin tardanza la Estrategia de Lisboa y proceder a una reorientación de las prioridades en dirección del crecimiento y del empleo. Europa debe renovar las bases de su competitividad, aumentar su potencial de crecimiento y su productividad y reforzar la cohesión social apostando, sobre todo, por el conocimiento, la innovación y la valorización del capital humano (Consejo, Reprs. Estados miembros reunidos en el Consejo 2005a:2).

Se estaba simplemente insistiendo en el mantra conocido: el aumento de la adaptabilidad de los trabajadores; la extensión legislativa de las posibilidades de la flexiseguridad; la creación y desarrollo de empresas, abaratando aún más los costes de mano de obra; atraer al mercado de trabajo a más personas; invertir en capital humano, sobre todo a través del aprendizaje permanente; simplificar y emancipar los mecanismos de gobernanza (simplificar y racionalizar los objetivos de la estrategia de Lisboa, es decir, simplificar el método abierto de coordinación), de las dialécticas políticas nacionales.

\section{El triunfo de la flexiseguridad y la Estrategia 2020.}

Con la Estrategia 2020, el techno-corporatism europeo sigue operando en la línea de continuidad con la revolución del mercado de trabajo que se inauguró en la Unión Europea a partir de Essen (1995), pasando por la reforma del Tratado de Ámsterdam (1997), con la puesta en marcha de la EEE en Luxemburgo (1997) y, de forma especial, con la Estrategia de Lisboa en el año 2000 y sus revisiones periódicas. Aunque las formulaciones retóricas parecen 
quedarse invariadas o mejor reforzadas, el contexto económico y social ha mudado radicalmente. Desde el punto de vista del contexto políticometodológico, por ejemplo, algunos países promotores de la cooperación europea, como Francia y Países Bajos, en el 2007 han votado en contra de la introducción de la Constitución Europea, obligando la gobernance europea a ejecutar el Tratado de Lisboa para a circunnavegar el poder popular y la dialéctica democrática salvaguardando así los intereses de la Constitución rechazada (Attac Europa 2008). Por lo que concierne al contexto políticoeconómico, el impacto del Fondo Social Europeo (FSE), principal instrumento financiero para el desarrollo y la ocupación en las áreas en dificultad, empieza a ser poco influyente y los países que más habían obtenido beneficios, como España, Irlanda, Italia Portugal y Grecia, comienzan a sufrir económica y socialmente la crisis financiera. Los benchmarks europeos, finalmente, han sido nunca alcanzados y la mayoría de las proposiciones políticas, sobre todo las referidas a la Europa Social y a la seguridad del empleo quedaron solo en la retórica política de una hegemonía económico-gubernamental que ha tenido como finalidad privatizar todo el patrimonio público, en términos de servicios, infraestructuras, y protección social, flexibilizar el mercado del trabajo extendiendo la precarización a todo el arco de la vida con los nuevos sistemas de PES; destruyendo, en fin, definitivamente lo que quedaba de la idea política de estado de bienestar y de derechos sociales (Allulli 2010). Así que cuando se hace pública la consciencia de la crisis financiera en 2009-2010, la respuesta de la Unión para emerger de tal situación económico-social ha sido proponer la estrategia Europa 2020 (2010a) siguiendo en todo los aspectos y los principios la Estrategia de Lisboa, proponiendo lo que definen de economía social de mercado para la próxima década, adoptando todas las soluciones posibles para constringir aún más las políticas sociales e intervenir sobre todas aquellas categorías de trabajadores y grupos sociales que aún seguían dentro de algún tipo de protección o contrato social ${ }^{9}$. Con Europa 2020 se proponen, en efecto, tres objetos prioritarios que amplían los establecidos en el marco de la Estrategia de Lisboa. A saber, con el crecimiento inteligente se sigue el desarrollo del paradigma de la economía basada en el conocimiento y la innovación; el crecimiento sustentable indica un nuevo campo de explotación en el mercado de las energías renovables, de las innovaciones en materia de bajas emisiones, de la gestión de recursos y de la competitividad; el crecimiento inclusivo mira, a través del instrumento de la flexiseguridad, la inclusión diferencial y la reducción de la segmentación entre trabajadores insider y outsider (con el favor de las políticas de cohesión social y territorial). La gobernanza europea, en el marco del tratado de Lisboa, sigue así su metodología de acción a largo plazo con planes y ajustes que serán evaluados

\footnotetext{
${ }^{9}$ En 2008, la Comisión Europea presentó Un Plan Europeo de Recuperación Económica (Comisión de las Comunidades Europeas 2008c). En 2009 y en la primavera de 2010 (Consejo, Reprs. Estados miembros reunidos en el Consejo 2009b) el gobierno alemán empuja a los demás Estados miembros a la adopción de un paquete normativo veinteñal que mirase a la aplicación del Equilibrio presupuestario: esto llevará a una rigurosa aplicación del requisito de la relación déficit/PIB inferior al 3\% con un impacto notable (y desastroso) sobre el futuro económico y social de la Europa periférica, para las próximas dos décadas. El Tratado de Estabilidad, Coordinación y Gobernanza en la Unión Económica y Monetaria (comúnmente conocido como el "Pacto Presupuestario") entró en vigor el 1 de enero de 2013 una vez ratificado por Finlandia (Consejo, Reprs. Estados miembros reunidos en el Consejo 2012).
} 
sobre la base de cinco principales metas cuantitativas a nivel común ${ }^{10}$, que los Estados miembros tendrán que traducir en objetivos nacionales definidos en función de las respectivas situaciones.

Tabla 6 : Las siete iniciativas emblemáticas de Europa 2020

\begin{tabular}{|c|c|}
\hline $\begin{array}{l}\text { Unión por la } \\
\text { innovación }\end{array}$ & $\begin{array}{l}\text { Mejorar las condiciones generales y el acceso a la } \\
\text { financiación para investigación e innovación y garantizar que } \\
\text { las ideas innovadoras se puedan convertir en productos y } \\
\text { servicios que generen crecimiento y empleo }\end{array}$ \\
\hline $\begin{array}{l}\text { Juventud en } \\
\text { movimiento }\end{array}$ & $\begin{array}{l}\text { Mejorar los resultados de los sistemas educativos y facilitar } \\
\text { la entrada de los jóvenes en el mercado de trabajo }\end{array}$ \\
\hline $\begin{array}{l}\text { Una agenda digital } \\
\text { para Europa }\end{array}$ & $\begin{array}{l}\text { Acelerar el despliegue de internet de alta velocidad y } \\
\text { beneficiarse de un mercado único digital para las familias y } \\
\text { empresas }\end{array}$ \\
\hline $\begin{array}{l}\text { Una Europa que } \\
\text { utilice eficazmente } \\
\text { los recursos }\end{array}$ & $\begin{array}{l}\text { Ayudar a desligar crecimiento económico y utilización de } \\
\text { recursos, apoyar el cambio hacia una economía con bajas } \\
\text { emisiones de carbono, incrementar el uso de fuentes de } \\
\text { energía renovables, modernizar nuestro sector del } \\
\text { transporte y promover la eficacia energética }\end{array}$ \\
\hline $\begin{array}{l}\text { Una política } \\
\text { industrial para la era } \\
\text { de la mundialización }\end{array}$ & $\begin{array}{l}\text { Mejorar el entorno empresarial, especialmente para las } \\
\text { PYME, y apoyar el desarrollo de una base industrial fuerte y } \\
\text { sostenible, capaz de competir a nivel mundial }\end{array}$ \\
\hline $\begin{array}{l}\text { Agenda de nuevas } \\
\text { cualificaciones y } \\
\text { empleos }\end{array}$ & $\begin{array}{l}\text { Modernizar los mercados laborales y potenciar la autonomía } \\
\text { de las personas mediante el desarrollo de capacidades a lo } \\
\text { largo de su vida con el fin de aumentar la participación } \\
\text { laboral y adecuar mejor la oferta y la demanda de trabajos, } \\
\text { en particular mediante la movilidad laboral }\end{array}$ \\
\hline $\begin{array}{l}\text { Plataforma europea } \\
\text { contra la pobreza }\end{array}$ & $\begin{array}{l}\text { Garantizar la cohesión social y territorial de tal forma que los } \\
\text { beneficios del crecimiento y del empleo sean ampliamente } \\
\text { compartidos y las personas que sufren de pobreza y } \\
\text { exclusión social puedan vivir dignamente y tomar parte } \\
\text { activa en la sociedad }\end{array}$ \\
\hline
\end{tabular}

Fuente: (Comisión de las Comunidades Europeas 2010a)

Los planes decenales han sido adoptados también en el campo formativo con la definición de un cuadro para la cooperación europea para los próximos diez años que acompañe las acciones de Europa 2020. El programa Education and Training 2020 (ET 2020) basado en sus antecesores, el programa de trabajo Educación y Formación 2010 (ET 2010) y en la Comunicación de la Comisión Nuevas Capacidades para Nuevos Empleos (2008a), a la luz de las previsiones sobre la evolución de la ocupación y sobre las necesidades de competencias en Europa estimadas por Cedefop hasta el 2020, sugiere a los Estados miembros acciones centradas en la capacidad de reorientar la oferta de educación y formación con base en la demanda de las empresas y las necesidades profesionales del sistema productivo.

10

- $\quad$ El $75 \%$ de la población de entre 20 y 64 años debería estar empleada.

- $\quad$ El 3\% del PIB de la UE debería ser invertido en I+D.

- Alcanzar el objetivo «20/20/20» en materia de clima y energía (incluido un incremento al $30 \%$ de la reducción de emisiones si se dan las condiciones para ello).

- $\quad$ El porcentaje de abandono escolar debería ser inferior al $10 \%$ y al menos el $40 \%$ de la generación más joven debería tener estudios superiores completos.

- $\quad$ El riesgo de pobreza debería amenazar a 20 millones de personas menos. 
Gráfico 5: Past and likely future occupational employment structure, EU-27+

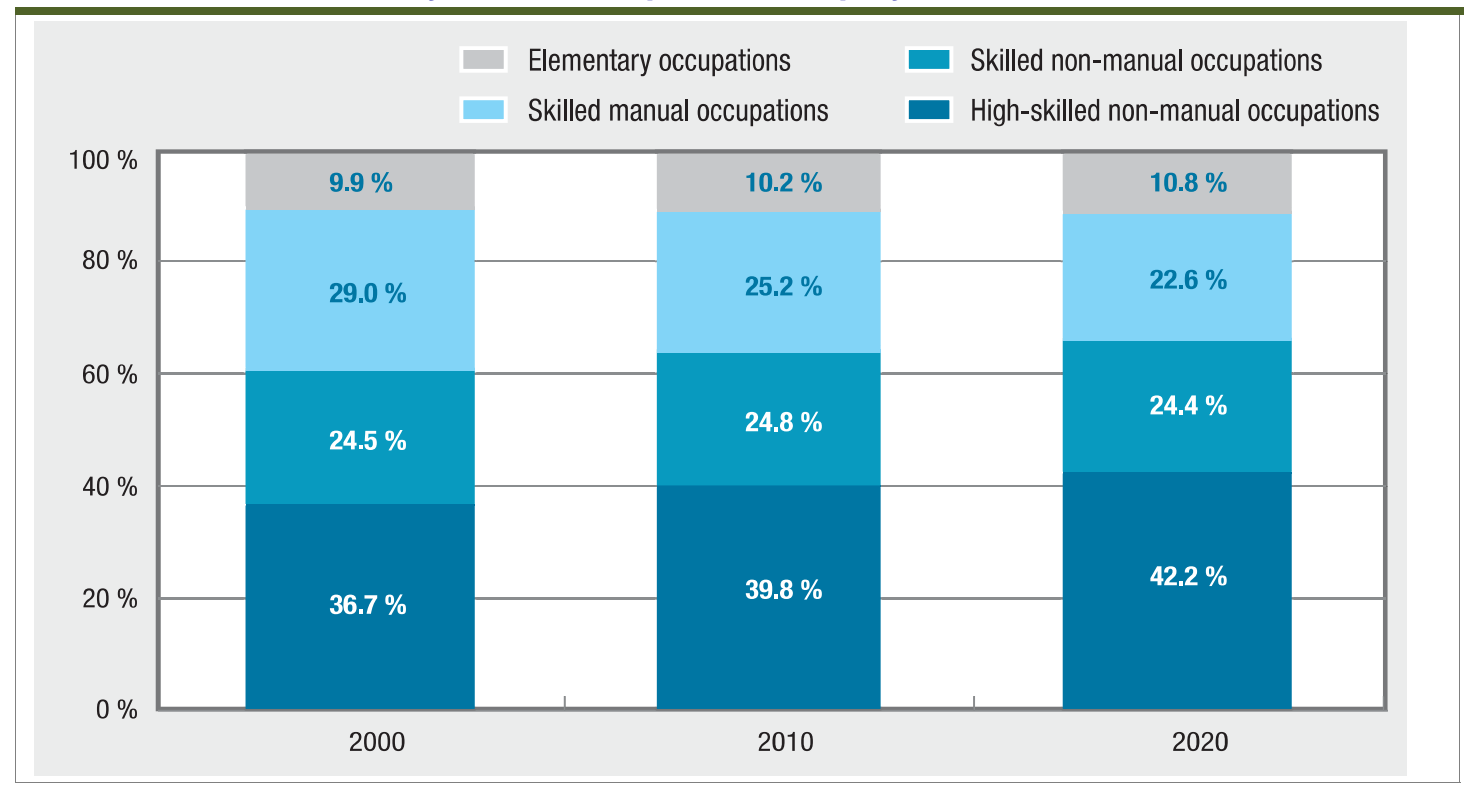

NB: Numbers in employment (NA-based estimates)

Fuente: (Cedefop 2010:59)

Cedefop calcula que el mercado del trabajo en la UE tiene que evolucionar hasta 2020 de esta forma:

- Dos tercios de la ocupación europea se concentrará en el sector terciario.

- Casi toda la ocupación añadida y una fuerte componente de la sustitutiva serán caracterizadas por trabajo de alta intensidad de conocimiento y competencias técnicas.

- Crecerán los niveles de educación/formación y las competencias requeridas en todos los campos de trabajo, también en las ocupaciones elementales.

En este escenario, se observa la declive de la ocupación y de los trabajos de rutina, tanto en el sector industrial como en el terciario.

Gráfico 6: The changing occupational structure of employment, EU-27+

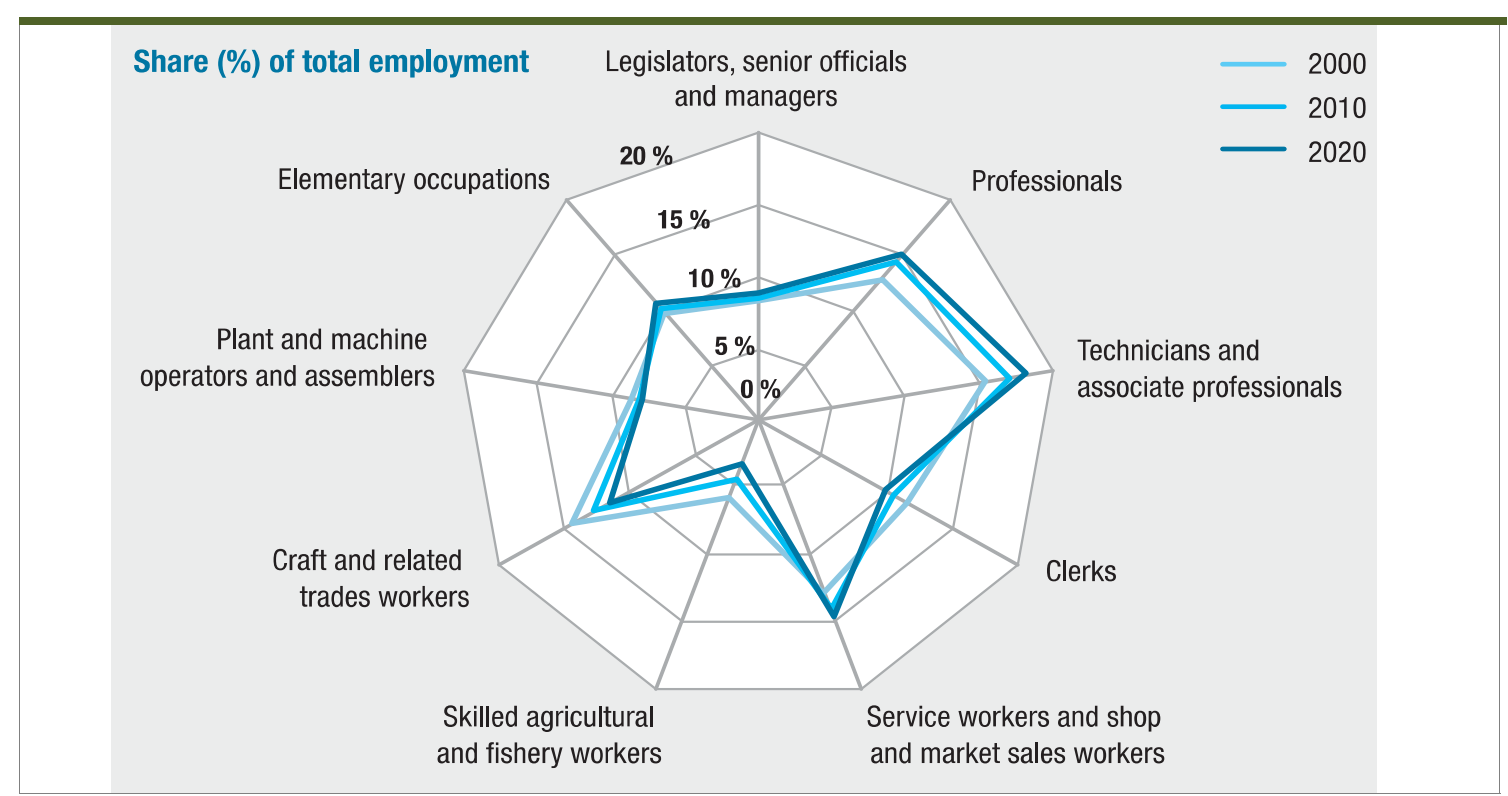

Fuente: (Cedefop 2010:58) 
La revolución digital ha sustituido, en efecto, muchos de los viejos empleos e influido en la creación de nuevas formas de trabajar. Muchas producciones y servicios en rutina se deslocalizan en países donde la protección social y el coste de la mano de obra es menor. Al abaratar estos costes, la economía de los países centrales invierten así solo y exclusivamente en calidad e innovación, pidiendo competencias específicas de un campo y, al mismo tiempo, amplias para ser intercambiadas y compartidas. Y esto ocurre también en aquellos empleos que podemos definir de elementales donde, por ejemplo, se pide a los trabajadores conocer productos y técnicas de utilización, saber comunicar y resolver problemas. De acuerdo al informe de Cedefop, los niveles de calificación han crecido y crecerán más, sobre todo en aquellas componentes juvenil y femenil de la fuerza trabajo. Por lo que concierne al método de actuación del programa Education and Training 2020 (Consejo, Reprs. Estados miembros reunidos en el Consejo 2009a) continúa con el MAC e identifica cuatro puntos estratégicos a largo plazo:

- Hacer realidad el aprendizaje permanente y la movilidad de los educandos.

- Mejorar la calidad y la eficacia de la educación y la formación.

- Promover la equidad, la cohesión social y la ciudadanía activa.

- Incrementar la creatividad y la innovación, incluido el espíritu empresarial, en todos los niveles de la educación y la formación

Como podemos observar, el programa reitera parte de los objetivos ya definidos en Copenhague, introduciendo además el objetivo de la innovación y la creatividad, en línea con la estrategia Europa 2020. Según el Consejo, la creatividad y la innovación son fundamentales para la creación de empresas y para la capacidad de Europa para competir a nivel internacional, sobre todo en el objetivo del crecimiento sustentable. Dentro de este nuevo cuadro común para la promoción de los sistemas de educación, formación y aprendizaje permanente, el Consejo de los Ministros Europeos para la educación y formación aprobó cinco nuevos objetivos cuantitativos (benchmark) para conseguir hasta el 2020:

Tabla 7: Los benchmarks de ET 2020

\begin{tabular}{|c|l|}
\hline $\begin{array}{c}\text { Participación de los } \\
\text { adultos en el aprendizaje } \\
\text { permanente }\end{array}$ & $\begin{array}{l}\text { Para 2020, una media de un 15\% como mínimo de los } \\
\text { adultos debería participar en el aprendizaje permanente }\end{array}$ \\
\hline $\begin{array}{c}\text { Personas que obtienen un } \\
\text { bajo rendimiento en } \\
\text { aptitudes básicas }\end{array}$ & $\begin{array}{l}\text { Para 2020, el porcentaje de jóvenes de quince años con un } \\
\text { bajo rendimiento en lectura, matemáticas y ciencias deberá } \\
\text { ser inferior al 15\%. }\end{array}$ \\
\hline $\begin{array}{c}\text { Rendimiento en materia de } \\
\text { enseñanza superior }\end{array}$ & $\begin{array}{l}\text { Para el año 2020, la proporción de personas con edades } \\
\text { comprendidas entre treinta y treinta y cuatro años que hayan } \\
\text { terminado la educación superior deberá ser de al menos un } \\
\text { 40\%. }\end{array}$ \\
\hline $\begin{array}{c}\text { Abandonos prematuros de } \\
\text { la educación y formación }\end{array}$ & $\begin{array}{l}\text { Para 2020, la proporción de abandono prematuro de la } \\
\text { educación y formación debería estar por debajo del 10\% }\end{array}$ \\
\hline Educación en la primera & $\begin{array}{l}\text { Para 2020, al menos un 95\% de los niños con edades } \\
\text { comprendidas entre los cuatro años y la edad de } \\
\text { infancia }\end{array}$ \\
\hline
\end{tabular}

Fuente: (Consejo, Reprs. Estados miembros reunidos en el Consejo 2009a) 
En resumen, el programa Education and Training 2020 se conjuga con las líneas de actuación prioritarias de Europa 2020 centrándose en el primero de los cuatro puntos fundamentales, o sea el fomento de la formación permanente (formación en ciclo vital). Sin embargo lo que realmente explica y sitúa la Estrategia 2020 de la UE en políticas de empleo es el debate en la adopción estratégica del instrumento flexiguridad o el nexo que subordina la seguridad a la flexibilidad en las directrices integradas, mediante el cual eliminar la segmentación del mercado del trabajo, gracias a políticas nacionales que busquen eliminar la protección al despido, así como crear las condiciones para una política activa de empleo:

Ejecutar planes nacionales de «flexiseguridad», según lo acordado por el Consejo Europeo, con objeto de reducir la segmentación del mercado laboral y facilitar las transiciones, así como facilitar la conciliación entre vida laboral y familiar (Comisión de las Comunidades Europeas 2010a: 20).

Hemos visto que con la revisión de la Estrategia Europea de Empleo de 2002 empezó a aparecer en las políticas de la UE la noción de flexiseguridad ${ }^{11}$, si bien la adopción "formal" de este planteamiento surge con el Libro Verde Modernizar el derecho laboral para afrontar los retos del siglo XXI (2006c). La flexiseguridad se instaura en el paradigma de las políticas activas de empleo, con el objetivo de absorber en la neutralidad dos acciones políticas dialécticamente contradictorias, con la paulatina subordinación de toda política de seguridad y protección social a los mercados de trabajo y a la organización del proceso productivo. Ello implica no solo flexibilidad interna en movilidad, en tiempo de trabajo, en reciclaje y aprendizaje permanente de competencias; también flexibilidad externa en la desregulación del mercado del trabajo, con la facilidad de extinguir y cambiar el contrato de trabajo. Se trata en fin del pasaje del welfare al workfare, en el cual la seguridad en el puesto de trabajo (como la calidad del mismo) se sustituye con la seguridad en el empleo, planteamiento que implica la puesta en marcha de políticas activas para la calidad del empleo y para el aprendizaje permanente, reduciendo hasta cancelar todas las prestaciones de desempleo para los parados (como todas las políticas pasivas de empleo). Gorelli Hernández, en su Crítica a la Flexiseguridad, identifica cuatro puntos principales en el modelo imperante de la política de empleo de la Unión Europea que se imponen con esta apología del aporismo:

- Modernizar el derecho del trabajo, que no es más que una fórmula para evitar reconocer expresamente que estamos ante la flexibilización del ordenamiento laboral: difundir modalidades atípicas de contratación, especialmente el contrato a tiempo parcial, facilitar mecanismos de reorganización productiva a la empresa o, lo que es igual, movilidad interna (movilidad funcional,

11 La Comisión defiende la idea de flexiseguridad, en orden cronológico, con cuatro instrumentos clave:

- Libro Verde Modernizar el Derecho laboral para afrontar los retos del siglo XXI (2006);

- Comunicación Hacia los principios comunes de la flexiguridad: más y mejor empleo mediante la flexibilidad y la seguridad (2007);

- Comunicación Europa 2020: una estrategia para un crecimiento inteligente, sostenible e integrador (2010);

- Propuesta de Decisión del Consejo sobre directrices para las políticas de empleo de los Estados Miembros. Parte II de las Directrices Integradas Europa 2020 (2010). 
geográfica, modificaciones sustanciales, reducciones del tiempo de trabajo, flexibilidad salarial) o externa (extinción).

- Formación y aprendizaje a lo largo de toda la vida, facilitando la transición de la formación al trabajo, así como incrementar la empleabilidad de los trabajadores y su cualificación.

- Políticas activas que permitan que los periodos de transición sean lo más rápido posible, mejorando la actuación de los servicios públicos, sobre todo a través de la individualización del tratamiento de los que buscan empleo y a través de prestar una especial atención a los colectivos con mayor dificultad de acceso al empleo.

- Por último, es imprescindible la mejora de los sistemas de seguridad social que también deben modernizarse, facilitando una mayor y mejor protección (si bien condicionada a la activación) a los desempleados" (Gorelli Hernández 2013:57).

La Comisión utiliza así la flexiseguridad para continuar con las reformas que incrementen un modelo de flexibilidad laboral, al mismo tiempo que, como un slogan, se promocione la seguridad para los trabajadores. En realidad, los gobiernos nacionales, bajo el tema de la flexiseguridad han ido introduciendo el anatema de la flexibilidad en los márgenes, es decir, han aumentado la flexibilidad de los contratos atípicos y temporales al mismo tiempo que han dado vía libre al despido fácil. Los técnicos de la Comisión, en efecto, construyen una representación sesgada en el discurso público de la existencia de una legislación rígida sobre la protección del empleo que supuestamente reduce el dinamismo del mercado de trabajo, agravando la desregulación "en los márgenes"; o dicho de otra manera: para mantener la protección frente al despido de los insiders hay que desproteger a los outsiders; de esta manera, un exceso de protección del empleo implica la segmentación del mercado de trabajo. Lo que se plantea, en efecto, es la reducción del coste del despido o, simplemente, facilitarlo a cambio de incrementar la tutela desde el punto de vista de las prestaciones por desempleo y de medidas activas orientadas a conseguir nuevos empleos. Sin lugar a dudas podemos afirmar que este es el instrumento que el techno-corporatism europeo utiliza para reducir aún más la tutela laboral, planteándose como un mecanismo que pone en antagonismo el derecho del trabajo con el derecho al trabajo.

Una estrategia, la de Europa 2020, que como hemos visto interviene en la revisión de los mecanismos clásicos de la flexibilidad tradicional, continúa en línea con las estrategias de empleo en clave desreguladora (respecto a las garantías del derecho del trabajo): desde la liberalización y abaratamiento del despido, al cambio hacia unas políticas activas de empleo que abren un espacio a nuevos y creativos sentidos seguridad social. Sin embargo, cabe mencionar en este nivel de análisis coyuntural de los procesos hegemónicos europeos, que estas políticas se están llevando a cabo en orden a las nuevas medidas de austerity de las economías periféricas europeas han adoptado, en base a la denominada operación de "rescate" por endeudamiento público y privado de los respectivos sistemas económicos. De esta forma, cuando hablamos de la innovación del paradigma de la seguridad a través del nuevo rumbo de políticas activas de empleo, estamos resumiendo procesos siempre más agudos de desregulación de las protecciones sociales clásicas, que pasan tanto por la reducción drástica del gasto social y de la inversión y gasto público en materia de prestaciones económicas del sistema de Seguridad Social, como 
por la privatización y terciarización de las prestaciones sociales. Al final, por tanto, la política económica y financiera de la Unión Europea frente a la crisis, encuentra su aliado en la Estrategia Europea para el Empleo amplificando el proceso hegemónico que definimos de revolución permanente $\mathrm{y}$, al mismo tiempo, obteniendo una cierta legitimación social y colectiva. Un proceso hegemónico que ve a los organismos, las instituciones y las agencias de la Unión Europea, desplazar lo que Coutinho define como de gran política (2011), o sea, la confrontación y dialéctica político-social de los Estados miembros en un nivel tecnocrático.

Es por lo tanto gran política el tratar de excluir la gran política del ámbito interno de la vida estatal y reducir todo a pequeña política (Gramsci 1999:V-Q13: 20).

El sistema de coordinación y recomendación de la nueva gobernanza europea, en efecto, se limita a fijar aquellas coordenadas políticas, administrativas y sociales fundamentales, indiscutibles y a largo plazo, que resuelven los ajustes y los cambios político-económicos según una perspectiva evolutiva, o sea desvaneciendo y declinando, respecto a los pasajes de la confrontación social, la dialéctica política nacionales y la conflictividad social.

\section{Bibliografía}

Allulli, Giorgio. 2010. Dalla strategia di Lisbona a Europa 2020. Politiche Europee della Formazione, Roma.

Attac Europa. 2008. Opuscolo degli Attac Europei sul Trattato di Lisbona e l'UE, secondo i "10 principi." Attac Europa.

Biagi, Marco. 1998. The Implementation of the Amsterdam Treaty with regard to Employment: Co-ordination or Convergence? International Journal of Comparative Labour Law and Industrial Relations 14: 325-336.

Biagi, Marco. 2000. L'impatto della European Employment Strategy sul ruolo del diritto del lavoro e delle relazioni industriali. Riv. it. dir. lav: 413.

Bolívar, Antonio. 2008. El discurso de las competencias en España: educación básica y educación superior. REDU. Revista de Docencia Universitaria 6: 1-23.

Bolívar, Antonio, and Amador Guarro Pallás. 2007. Educación y cultura democráticas: Proyecto Atlántida. WK Educación.

Cabeza Pereiro, Jaime, and María Amparo Ballester Pastor. 2012. La Estrategia Europea para el empleo 2020 y su repercusiones en el ámbito jurídico laboral español. Revista del Ministerio de Empleo y Seguridad Social: 388-394.

Cedefop. 2010. Skills supply and demand in Europe. Medium-term forecast up to 2020. Luxemburgo: Office for Official Publications of the European Communities.

Comisión de las Comunidades Europeas. 2000. eLearning - Concebir la educación del futuro. Oficina de Publicaciones Oficiales de las Comunidades Europeas. 
Comisión de las Comunidades Europeas. 2001. Hacer realidad un espacio europeo del aprendizaje permanente. Office for Official Publications of the European Communities.

Comisión de las Comunidades Europeas. 2002. COMUNICACIÓN DE LA COMISIÓN AL CONSEJO, AL PARLAMENTO EUROPEO, AL COMITÉ ECONÓMICO Y SOCIAL Y AL COMITÉ DE LAS REGIONES Balance de cinco años de aplicación de la estrategia Europea de Empleo. Oficina de Publicaciones Oficiales de las Comunidades Europeas.

Comisión de las Comunidades Europeas. 2003. COMUNICACIÓN DE LA COMISIÓN AL CONSEJO, AL PARLAMENTO EUROPEO, AL COMITÉ ECONÓMICO Y SOCIAL Y AL COMITÉ DE LAS REGIONES El futuro de la Estrategia Europea de Empleo (EEE) «Una estrategia para el pleno empleo y mejores puestos de trabajo para todos». Oficina de Publicaciones Oficiales de las Comunidades Europeas.

Comisión de las Comunidades Europeas. 2004. Competencias clave para un aprendizaje a lo largo de la vida. Un marco de referencia europeo. Direccion general de educación y cultura. Oficina de Publicaciones Oficiales de las Comunidades Europeas.

Comisión de las Comunidades Europeas. 2005. Comunicación al Consejo Europeo. Trabajando juntos por el crecimiento y el empleo. Relanzamiento de la estrategia de Lisboa. Oficina de Publicaciones Oficiales de las Comunidades Europeas.

Comisión de las Comunidades Europeas. 2006a. COMUNICACIÓN DE LA COMISIÓN AL CONSEJO Y AL PARLAMENTO EUROPEO. Cumplir la agenda de modernización para las universidades: educación, investigación e innovación. Oficina de Publicaciones Oficiales de las Comunidades Europeas.

Comisión de las Comunidades Europeas. 2006b. Libro verde. Modernizar el Derecho laboral para afrontar los retos del siglo XXI. Oficina de Publicaciones Oficiales de las Comunidades Europeas.

Comisión de las Comunidades Europeas. 2008a. Un Plan Europeo de Recuperación Económica. Oficina de Publicaciones Oficiales de las Comunidades Europeas.

Comisión de las Comunidades Europeas. 2008b. COMUNICACIÓN DE LA COMISIÓN AL CONSEJO Y AL PARLAMENTO EUROPEO. NuevaS Capacidades para Nuevos Empleos Previsión de las capacidades necesarias y su adecuación a las exigencias del mercado laboral. Oficina de Publicaciones Oficiales de las Comunidades Europeas.

Comisión de las Comunidades Europeas. 2010. EUROPA 2020. Una Estrategia para un crecimiento inteligente, sostenible e integrador. Office for Official Publications of the European Communities.

Comisión de las Comunidades Europeas. 2012. EU Budget 2011: Financial Report. Publications Office of the European Union.

Consejo, Reprs. Estados miembros reunidos en el Consejo. 2000. Conclusiones de la Presidencia: Consejo Europeo de Lisboa: 23 y 24 de marzo de 2000. Diario Oficial de la Unión Europea. 
Consejo, Reprs. Estados miembros reunidos en el Consejo. 2003. DECISIÓN DEL CONSEJO relativa a las Directrices para las políticas de empleo de los Estados miembros. Diario Oficial de la Unión Europea.

Consejo, Reprs. Estados miembros reunidos en el Consejo. 2005. Concluciones de la Presidencia. Consejo Europeo de Bruselas. Diario Oficial de la Unión Europea.

Consejo, Reprs. Estados miembros reunidos en el Consejo. 2009a. Reglamento (CE) $n^{\circ}$ 479/2009 del Consejo, de 25 de mayo de 2009, sobre el procedimiento aplicable en caso de déficit excesivo, anejo al Tratado constitutivo de la Comunidad Europea (versión codificada). Diario Oficial de la Unión Europea.

Consejo, Reprs. Estados miembros reunidos en el Consejo. 2009b. ET 2020. Conclusiones del Consejo de 12 de mayo de 2009 sobre un marco estratégico para la cooperación europea en el ámbito de la educación y la formación. Diario Oficial de la Unión Europea.

Consejo, Reprs. Estados miembros reunidos en el Consejo. 2012. TRATADO DE ESTABILIDAD, COORDINACIÓN Y GOBERNANZA EN LA UNIÓN ECONÓMICA Y MONETARIA. Diario Oficial de la Unión Europea.

Coutinho, Carlos Nelson. 2011. L'epoca neoliberale e l'egemonia della piccola politica. In Dialettica, storia e conflitto. II proprio tempo appreso nel pensiero. La Scuola di Pitagora.

Egeberg, Morten, and Jarle Trondal. 2011. Agencification and location: Does agency site matter? Public Organization Review 11: 97-108.

ERT. 2000. Enhancing European Competitiveness - our core concern. European Round Table of Industrialists.

ERT. 2001. Actions for Competitiveness Through the Knowledge Economy in Europe: Message from the European Round Table of Industrialists to the Stockholm European Council, March 2001. European Round Table of Industrialists.

Eurydice. 2012. The european higher education area in 2012. Bologna process implementation report. Bruxelles: Eurydice.

Fischer, Frank. 1990. Technocracy and the Politics of Expertise. New York: SAGE Publications.

González, Julia, and Robert Wagenaar. 2003. Quality and European programme design in higher education. European Journal of Education 38: 241-251.

González, Julia, and Robert Wagenaar. 2006. Tuning educational structures in Europe: Universities' contribution to the Bologna process: an introduction. Socrates and Tempus programmes. University of Deusto: Edited by Julia González and Robert Wagenaar.

Gorelli Hernández, Juan. 2013. Crítica a la flexiseguridad. Revista Latinoamericana de Derecho Social. 
Gramsci, Antonio. 1999. Cuadernos de la carcel. Edited by Valentino Gerratana, Antonio Gramsci. Ediciones Era/Universidad Autonoma de Puebla. 6 vols. Mexico, DF: Ediciones Era.

Hernández, Juan Gorelli. 2012. La política de empleo en Europa y la evolución de sus "estrategias". In Política y servicios publicos de empleo. Una visión europea en conexión con el mundo universitario. Editorial Bomarzo.

Hix, Simon. 1998. The study of the European Union II: the "new governance" agenda and its rival. Journal of European Public Policy 5: 38-65.

Kok, Wim. 2004. Facing the Challenge: The Lisbon Strategy for Growth and Employment: Report from the Higher Level Group. Office for official publications of the European communities.

Martinico, Giuseppe. 2009. The Impact of the Open Method of Coordination on the «Form of Union». Diritto pubblico 15: 625-652.

OECD. 2001. PISA Knowledge and Skills for Life First Results from PISA 2000: First Results from PISA 2000. OECD Publishing.

Parlamento Europeo, and Consejo, Reprs. Estados miembros reunidos en el Consejo. 2006. DECISIÓN NO 1982/2006/CE DEL PARLAMENTO EUROPEO Y DEL CONSEJO relativa al Séptimo Programa Marco de la Comunidad Europea para acciones de investigación, desarrollo tecnológico y demostración (2007 a 2013). Diario Oficial de la Unión Europea.

Rama, Claudio. 2008. La Educacion de la sociedad del conocimiento. In . Puebla: ANUIES - BUAP.

Sierra Caballero, Francisco. 2006. Políticas de Comunicación y Educación: Crítica y desarrollo de la Sociedad del Conocimiento. Barcelona: Gedisa.

Uncetabarrenechea, Javier. 2009. Los riesgos de una relevancia excesiva de la competividad para el proceso de integración europea: una mirada crítica a la Estrategica de Lisboa. In Crisis económica y financiera: el papel de la Unión Europea, EUROBASK, 115-156. PREMIO DE INVESTIGACIÓN FRANCISCO JAVIER DE LANDABURU UNIVERSITAS VIII. Consejo Vasco del Movimiento Europeo Europako Mugimenduaren Euskal Kontseilua.

Vercellone, Carlo. 2002. Les politiques de développement à l'heure du capitalisme cognitif. Multitudes: 11-21.

Yániz Álvarez de Eulat, Concepción. 2006. Planificar la enseñanza universitaria para el desarrollo de competencias. Educatio siglo XXI 24: 17-34. 